\title{
COMPARING PARTICLE SIZE DISTRIBUTION ANALYSIS BY SEDIMENTATION AND LASER DIFFRACTION METHOD
}

\author{
Vito Ferro, Stefano Mirabile
}

\section{Generalities}

Particle-size distribution (PSD) is a fundamental physical property of a soil and it is typically presented as percentage of the total dry weight of soil occupied by a given size fraction.

Particles of sand size $(0.05-2.00 \mathrm{~mm})$ are usually determined by sieving. The sieve defines a particle diameter as the length of the side of a square hole through which the particle can just pass [Konert 1997].

Smaller particles are usually determined by classic sedimentation methods as hydrometer or pipette [Gee 1986]. Sieving combined with Hydrometer Method (SHM) has been adopted as an international standard to determine quantitatively the PSD of soils [Cooper 1984].

Using similar pretreatment techniques, the pipette and hydrometer methods give comparable results [Liu 1996; Walter 1978]; however the pipette method requires that clay and silt fraction $(<0.05 \mathrm{~mm})$ have to be separated from the sand fraction using wet sieving.

The pipette or the hydrometer method defines a particle diameter as equivalent to that of a sphere settling in the same liquid with the same speed as the unknown sized particles, the so-called "Stokes diameter" [Konert 1997]. The sphere is usually assigned to the density of quartz.

The sedimentation methods are time consuming, especially for the determination of the particles having a size less than $2 \mu \mathrm{m}$, require relatively large samples (10-20 $\mathrm{g}$ for the pipette and $50 \mathrm{~g}$ for the hydrometer) and give unreliable results for particles having a size less than $1 \mu \mathrm{m}$ because of the effect of Brownian motion on the rate of sedimentation.

Hydrometer analysis uses a hydrometer, having a graduated stem and weight bulb, to measure the spe-

Paper received 27.06.2008; accepted 30.04.2009

Prof. VITO FERRO, Ordinario di "Idraulica agraria e Sistemazioni idraulico-forestali”, Ing. Stefano Mirabile, Tecnico Cat. D, Dipartimento di Ingegneria e Tecnologie Agroforestali, Università di Palermo, Viale delle Scienze, 90128, Palermo, vferro@unipa.it cific density of the suspension. The specific density depends on the weight of soil particles in the suspension at the time of measurement [Wen 2002].

The hydrometer method is based on Stokes' law that, as it is known, establishes the velocity at which particle settles in suspension assuming that: (1) soil particles are rigid, spherical and smooth; (2) soil particles have similar densities; (3) particle-to-particle interference and boundary effects from the walls of the sedimentation column are negligible; (4) particle sizes are small enough to ensure that the induced fluid flow is well within the laminar flow regime. A particle size calculated by Stokes' law is a quartz equivalent spherical sedimentation diameter [McCave 1991].

Deviations from Stokes' equation are expected when the particle are irregular in shape, as most silty particles, or platy or tubular as clay particles. The particle-shape effect is due to the circumstance that the most stable position of a settling nonspherical particle is the one in which the maximum cross-sectional area is perpendicular to the direction of motion. As a consequence, this position increases the expected particle drag resistance and reduces the settling velocity. In other words the particle-shape effect determines an overestimation of the fine size fraction.

The validity of the spherical assumption (1) has been examined in many papers in the past. Nettleship et al. [1997] established that the standard hydrometer analysis should not be recommended for submicron materials. Vitton and Saddler [1997], examining eleven soils by hydrometer and laser measurements, obtained that hydrometer indicates a higher percentage of fine particles than laser-diffraction measurements. Similarly Konert and Vandenberghe [1997] comparing the results obtained by pipette analysis and laser-diffraction technique concluded that particle size distributions were comparable for blocky quartz particles but highly different for platy clay particles. Recently Lu et al. [2000] carried out a theoretical analysis for determining the settling velocity of diskshaped and rod-shapes particles. The analysis showed that for disk-shaped and rod-shaped particles, having a size ranging from $0.1 \mu \mathrm{m}$ to $100 \mu \mathrm{m}$, the Stokes' law underestimates the maximum particles dimension 
by up to two orders of magnitude. Experimental results of Lu et al. [2000], using various techniques, also confirmed the underestimate errors of particle size inherent in hydrometer analysis.

For soil and earth materials, particle density is commonly taken constant and equal to $2.65 \mathrm{Mg} \mathrm{m}^{-3}$. Clifton et al. [1999] suggested that density of sediment particles can vary between 1.66 and $2.99 \mathrm{Mg} \mathrm{m}^{-3}$. A soil is composed of particles with different densities, which are mainly determined by their mineral compositions. The uncertainty of the actual particle density may strongly bias the particle size distribution [Wen 2002].

The hypothesis (3) is assured limiting the maximum concentration of soil into the suspension $(50 \mathrm{~g}$ of dry soil in $1000 \mathrm{cc}$ of suspension).

The assumption (4) is verified for an upper limit of the Reynolds number value ranging from 0.1 to 1 [Allen 1990; Bernhardt 1994]; these values correspond to free-falling spherical particles up to $2 \mathrm{~mm}$ in diameter [Lu, 2000].

Determination of particle-size distribution by a Laser Diffraction Method (LDM) has already interested soil scientists [McCave 1996; De Boer 1986; Buurman 1997; Beuselinck 1998; Pieri 2006], but its application has not replaced the labor-intensive classical methods (pipette (PM) or hydrometer (HM) method). According to Buurman et al. [1997] this reluctance mainly depends on three factors: (i) insufficient confidence in the results of LDM: studies on correlations of laser-clay determinations with pipette-clay or hydrometer-clay ones are still scarce, and the correlations usually deviate from 1:1; (ii) in many countries the PM or the HM has been accepted as in international standard for particle-size analysis of soils; and (iii) the high cost of the laser-diffraction equipment.

A particle diameter found by LDM is equivalent to a sphere giving the same diffraction as the particles does. A laser diffraction particle size analyzer sees the particle as a two-dimensional object and gives its grain size as a function of the cross-sectional area of that particle. Using a laser particle analyzer the following assumptions are made [Konert 1997]:

(1) the transformation of diffraction patterns to grain sizes is based on matrices, which are calculated for spheres. Thus the diffraction along the cross-sectional area of the particles is assigned to diffraction of spheres;

(2) orientation is assumed to be random even if the laser measurements are carried out in a continuous suspension in which the particles may be oriented with respect to its shape.

The use of LDM raises the question of how similar the laser grain-size measurements are to those obtained by a classic technique such as SHM. Loizeau et al. [1994], using some samples of fluvial and lacustrine sediments, found that the laser grain-size distribution underestimates the clay content respect to the classic sedimentation method and that this underestimation increased with increasing clay content. The
Authors were not able to establish if the clay underestimation derives from the mineralogical composition or from the particle shape. No conclusion was obtained about the effects on the other size classes.

In this paper, after a brief review of the Laser Diffraction Method, in order to investigate these problems a comparison between the particle size distribution obtained by SHM method and by LDM is carried out. The analysis is developed using 30 soil samples, having a different texture classification, sampled in Sicily.

\section{The Laser Diffraction Method (LDM)}

The principle of the Laser Diffraction Method (LDM) is that particles of a given size diffract light through a given angle. The angle of diffraction is inversely proportional to particle size, and the intensity of the diffracted beam at any angle is a measure of the number of particles with a specific cross-sectional area in the beam's path.

A parallel beam of monochromatic light passes through a suspension contained in a sample cell, and the diffracted light is focused onto some detectors. For calculating particle sizes from light intensity sensed by detectors, two diffraction theories are commonly used: the Fraunhofer diffraction model and the Mie theory.

Both theories assume that the particles have a spherical shape; in other words, the particle dimension is the optical spherical diameter, i.e. the diameter of the sphere having a cross-section area equivalent to the measured one by laser diffraction.

The Fraunhofer theory is based on the approximation that the laser beam is parallel and the detector is at a distance that is very large compared with the size of the diffracting particle. Fraunhofer theory becomes inapplicable when particle diameter is close to the wavelength $\lambda$ of light as the refraction of particles in this size range becomes appreciable [Loizeau 1994]. Fraunhofer diffraction model gives inaccurate results for particles smaller than $10 \lambda$ [De Boer 1986].

Matrices based on Fraunhofer theory are calculated from diffraction by the particles and differences in absorption and refraction indices have no effect on the calculated grain-size distribution. This hypothesis is not completely correct for organic matter since this may absorb some light. The Mie theory is a solution of the Maxwell equations describing propagation of the electromagnetic wave of light in space. This theory provides a solution for the case of plane wave on a homogeneous sphere of any size [Eshel 2004]. The Mie theory takes into account phenomena of transmission through the particle and therefore requires knowledge of the refractive index $R I$ of the tested soil. The refractive index of a material is a function both of particle size and material's composition. Taking into account that soils are generally multisized and polymineralic in nature, this circumstance can make difficult to choose a representative refractive index 
for a given soil.

The refractive index $R I$ is a complex number comprised of a real part $n_{r}$, representing the change in the velocity of light through the tested material compared with the velocity of light in vacuum, and an imaginary term $n_{i}$ which represents the transparency and absorptivity of the tested material.

According to Konert and Vandenberghe [1997] the Fraunhofer theory is well suited for non-spherical clay particles. On the contrary de Boer et al. [8] suggest that Fraunhofer model is not accurate enough for the determination of the clay-size fraction. Different Authors [Konert 1997; Loizeau 1994] concluded that the Fraunhofer theory overestimates clay fraction respect to the Mie model. Loizeau et al. [1994] also established that the Fraunhofer theory detects a significantly larger proportion of the clay measured by the sieving-pipette method than does the Mie theory.

The LDM allows to analyze small samples in a short time (5 - 10 min per sample), in other words, is suitable for a rapid and accurate analysis of a large number of samples (e.g. soil samples sampled in a basin, suspension samples caught during soil erosion events). LDM covers a wide range of grain sizes and may also be used to analyze non-dispersed samples.

Although the fully dispersed size distribution (ultimate grain-size distribution) is important with respect to certain soil chemical and physical properties, other relevant processes, such as soil erosion and sediment transport by overland flow, are dependent on the size distribution of soil aggregates (effective grain-size distribution) [Foster 1985; Di Stefano 2002].

\section{Materials and methods}

Soil samples were taken at various location in a Sicilian basin, named Imera meridionale, having an area of $2000 \mathrm{~km}^{2}$. The 30 samples were selected to represent a complete variety of soil texture classification. Table 1 lists, for each sample, the soil sample code, the sand $S A$, silt $S I$ and clay $C L$ fractions, expressed as percentage, determined by SHM, the USDA soil texture classification and the organic matter content $O M$ expressed as percentage.

For both SHM and LDM, soil samples were dried at $105^{\circ}$ and were gently crushed and dry sieved at 2 $\mathrm{mm}$ mesh-size.For each analyzed soil sample, $50 \mathrm{~g}$ were used for SHM analysis and $10 \mathrm{~g}$ were used for LDM. Each sample was treated with $\mathrm{H}_{2} \mathrm{O}_{2}$ to assure complete removal of organic material and was dispersed to remove aggregates by adding a sodium hexametaphosphate solution over night. For SHM analysis the pretreated sample $(50 \mathrm{~g})$ was firstly wet sieved through a $0.075 \mathrm{~mm}$ sieve. The fine fraction $(<75 \mu \mathrm{m})$ collected after wet sieving was transferred to standard cylinders for hydrometer analysis.
The coarse fraction retained by the $75 \mu \mathrm{m}$ sieve was oven-dried at $105^{\circ}$, weighed and sieved at 0.075 , $0.106,0.250,0.425,0.85$ and $2 \mathrm{~mm}$.

For LDM analysis the pretreated sample $(10 \mathrm{~g})$ was firstly wet sieved through a $710 \mu \mathrm{m}$ sieve. A pretreated sub-sample, having a volume of $1.5 \mathrm{ml}$, was introduced into the dispersion unit device of the laser particle analyzer, that contained $400 \mathrm{ml}$ of deionized water, for the measurement.

\begin{tabular}{|c|c|c|c|c|c|}
\hline $\begin{array}{l}\text { Sample } \\
\text { code }\end{array}$ & $\begin{array}{l}\text { SA } \\
{[\%]}\end{array}$ & $\begin{array}{l}\text { SI } \\
{[\%]}\end{array}$ & $\begin{array}{l}\mathrm{CL} \\
{[\%]}\end{array}$ & $\begin{array}{c}\text { USDA } \\
\text { Classification }\end{array}$ & $\begin{array}{l}\mathrm{OM} \\
{[\%]}\end{array}$ \\
\hline 111 & 81.4 & 7.6 & 11.0 & Loamy Sand & 2.93 \\
\hline 153 & 81.1 & 12.5 & 6.4 & Loamy Sand & 0.36 \\
\hline 82 & 74.6 & 16.4 & 9.0 & Sandy Loam & 0.94 \\
\hline 104 & 79.1 & 11.3 & 9.6 & Sandy Loam & 1.04 \\
\hline 112 & 75.1 & 12.7 & 12.2 & Sandy Loam & 1.00 \\
\hline 80 & 48.2 & 33.2 & 18.6 & Loam & 3.79 \\
\hline 100 & 27.5 & 47.6 & 24.9 & Loam & 3.90 \\
\hline 101 & 26.6 & 49.9 & 23.5 & Loam & 5.71 \\
\hline 72 & 8.6 & 75.0 & 16.4 & Silt Loam & 3.03 \\
\hline 85 & 19.7 & 73.4 & 6.9 & Silt Loam & 1.86 \\
\hline 88 & 24.4 & 67.6 & 8.0 & Silt Loam & 1.23 \\
\hline 64 & 46.7 & 22.4 & 30.9 & Sandy Clay Loam & 3.46 \\
\hline 66 & 49.7 & 21.7 & 28.6 & Sandy Clay Loam & 4.78 \\
\hline 67 & 47.7 & 25.8 & 26.5 & Sandy Clay Loam & 1.64 \\
\hline 73 & 37.6 & 23.8 & 38.6 & Clay Loam & 1.17 \\
\hline 86 & 27.2 & 42.9 & 29.9 & Clay Loam & 3.67 \\
\hline 3 & 33.8 & 37.7 & 28.5 & Clay Loam & 7.18 \\
\hline 93 & 34.5 & 37.4 & 28.1 & Clay Loam & 4.36 \\
\hline 96 & 19.1 & 46.0 & 34.9 & Silty Clay Loam & 1.15 \\
\hline 97 & 14.8 & 48.2 & 37.0 & Silty Clay Loam & 1.33 \\
\hline 109 & 12.5 & 48.6 & 38.9 & Silty Clay Loam & 0.58 \\
\hline 44 & 5.6 & 40.7 & 53.7 & Silty Clay & 1.53 \\
\hline 78 & 17.7 & 41.0 & 41.3 & Silty Clay & 1.23 \\
\hline 84 & 13.0 & 46.6 & 40.4 & Silty Clay & 0.77 \\
\hline 7 & 18.4 & 39.4 & 42.2 & Clay & 6.11 \\
\hline 8 & 15.3 & 37.3 & 47.4 & Clay & 3.29 \\
\hline 22 & 26.6 & 31.8 & 41.6 & Clay & 1.95 \\
\hline 5 & 18.0 & 34.7 & 47.3 & Clay & 4.03 \\
\hline 49 & 25.4 & 20.9 & 53.7 & Clay & 2.11 \\
\hline 133 & 14.2 & 35.3 & 50.5 & Clay & 0.32 \\
\hline
\end{tabular}

TABLE 1 - Textural data of the 30 samples of Imera meridionale basin. 
In this investigation the FRITSCH Laser Particle Sizer Analysette 22 - Economy version was used (Fig. 1 ). The manufacturer claims a working range of $0.1-$ $600 \mu \mathrm{m}$. For the LDM analysis the subsample is introduced into the dispersion unit device where, to maintain the random orientation of particles in suspension, automatic ultrasonicating function is applied during the run. The ultrasonic action is an efficient dispersion method but can be critical for the particle size distribution because although the clay coatings are quickly removed the quartz grain can be also broken up. According to Chappel [1998] a 3-min duration of ultrasonic action is appropriate for sample suspended in tap water. Taking into account that the samples of this investigation are pretreated with a sodium hexameta phospate Calgon solution an ultrasonic duration less than 3-min could be also appropriate.In order to prevent suspension from forming of gas bubbles during the movement of suspension into the dispersion unit device (Fig. 2), the stirrer velocity was set to 60-70 revolutions/s. The suspension is then pumped through a sample cell placed in the convergent laser beam and the forward scattered light falls on the 31 photosensitive sensor rings. Each run was set for $60 \mathrm{~s}$.

Prior to every run, the detectors are aligned, the background is measured and the sample dilution is controlled (to test that the used sub-sample volume allows a correct analysis). All operations are controlled by a personal computer.

\section{Results}

For studying the effect of the ultrasonic action samples 22 and 44 were used. Samples 22 and 44 were selected because they have the highest clay content of the data set and their grain-size distribution can be appreciably affected by clay particle aggregation. Figure 3 shows, for each tested sample, the particle size distribution corresponding to an ultrasonic duration equal to 1,2 and $3 \mathrm{~min}$. The PSD measured without the dispersion action of ultrasounds was also carried out to have a reference situation.Taking into account that no reliable difference was determined among the three particle size distributions, an ultrasonic duration equal to $2 \mathrm{~min}$ was used in present investigation. For testing the effect of a pretreatment of the soil sample by $\mathrm{H}_{2} \mathrm{O}_{2}$, four samples having a different organic matter content $(0.32,2.11,4.03$ and $7.18 \%$ ) were examined.

Figure 4, showing as an example two typical cases of agricultural soils ( $O M$ values less than 4\%), demonstrates that an effect of the pretreatment can be recognized in the particle size distribution for soil particle ranging from $0.002 \mathrm{~mm}$ to $0.1 \mathrm{~mm}$. Adding of $\mathrm{H}_{2} \mathrm{O}_{2}$ produces a shifting of PSD of Fig. 4 towards the smallest particle diameter values; in other words for a given particle diameter $d$ the particle size distribution corresponding to $\mathrm{H}_{2} \mathrm{O}_{2}$ pretreatment is characterized by a frequency value $F(d)$ greater than the one of the

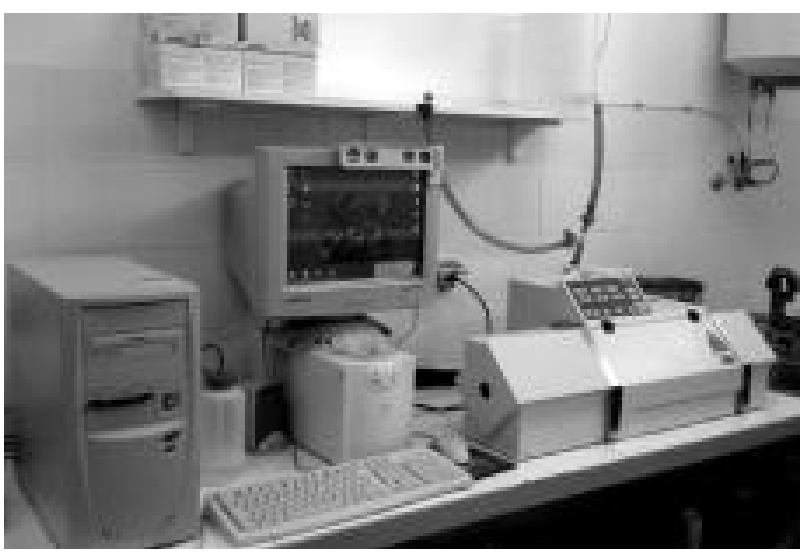

Fig. 1 - View of the Laser Particle Analyzer FRITSH Analysette 22.

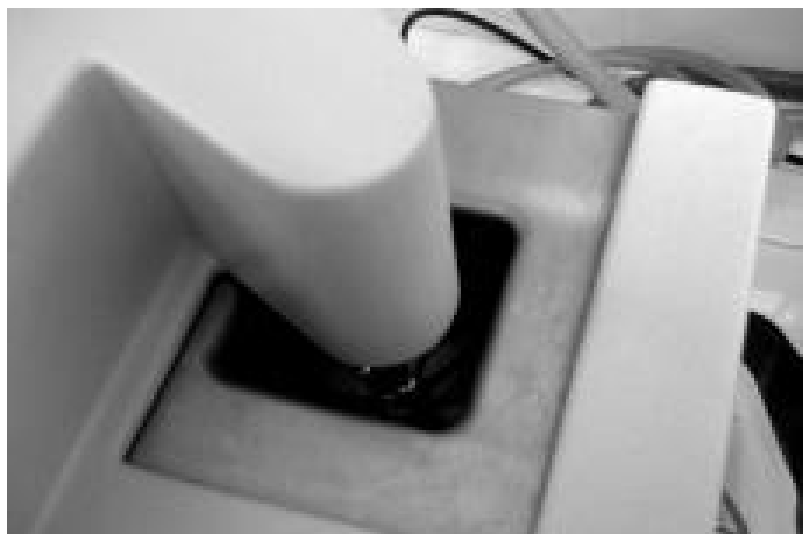

Fig. 2 - View of the dispersion unit device.
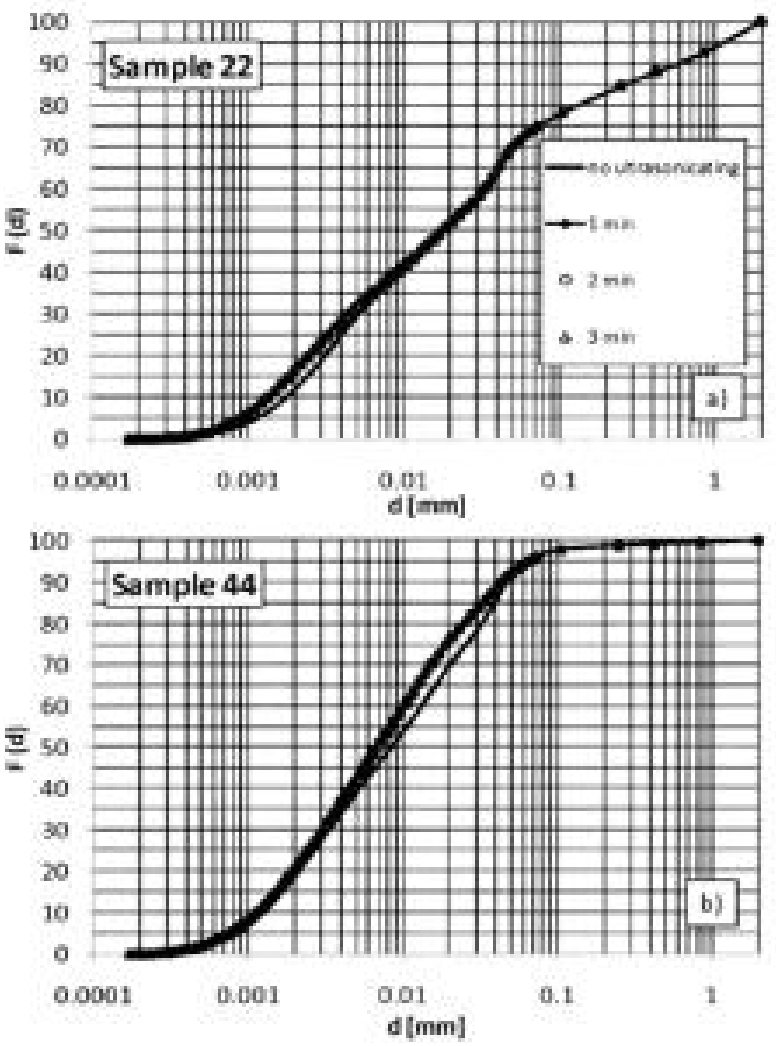

Fig. 3 - Particle size distributions corresponding to different ultrasonic durations. 
PSD corresponding to the condition "no $\mathrm{H}_{2} \mathrm{O}_{2}$ pretreatment". Removal of organic material determines that some soil particles which are originally aggregated become free from aggregation links.

Figure 5 clearly demonstrates that the absence of the $\mathrm{H}_{2} \mathrm{O}_{2}$ pretreatment determines a small both underestimation of clay fraction and overestimation of silt content.

Taking into account that the effect of the $\mathrm{H}_{2} \mathrm{O}_{2}$ pretreatment is not negligible, all samples analyzed in this investigation were pretreated.

For testing the effect of the used diffraction theory, the grain-size distribution of the samples 22 and 44 was determined using both the Fraunhofer diffraction model and the Mie theory. The first comparison was carried out using a refraction index characterized by a real part $n_{r}$ assuming two different values typical for the tested soils (1.5 and 1.6) and an imaginary term $n_{i}$ equal to 0.1 .

Figure 6 shows that no appreciable differences can be detected for the two investigated diffraction models applied to the selected samples. Figure 7 shows, for the same soil samples, that the variability of the imaginary term of the refraction index $(0.1-0.2)$ does not produce appreciable effects on the grain size distribution.
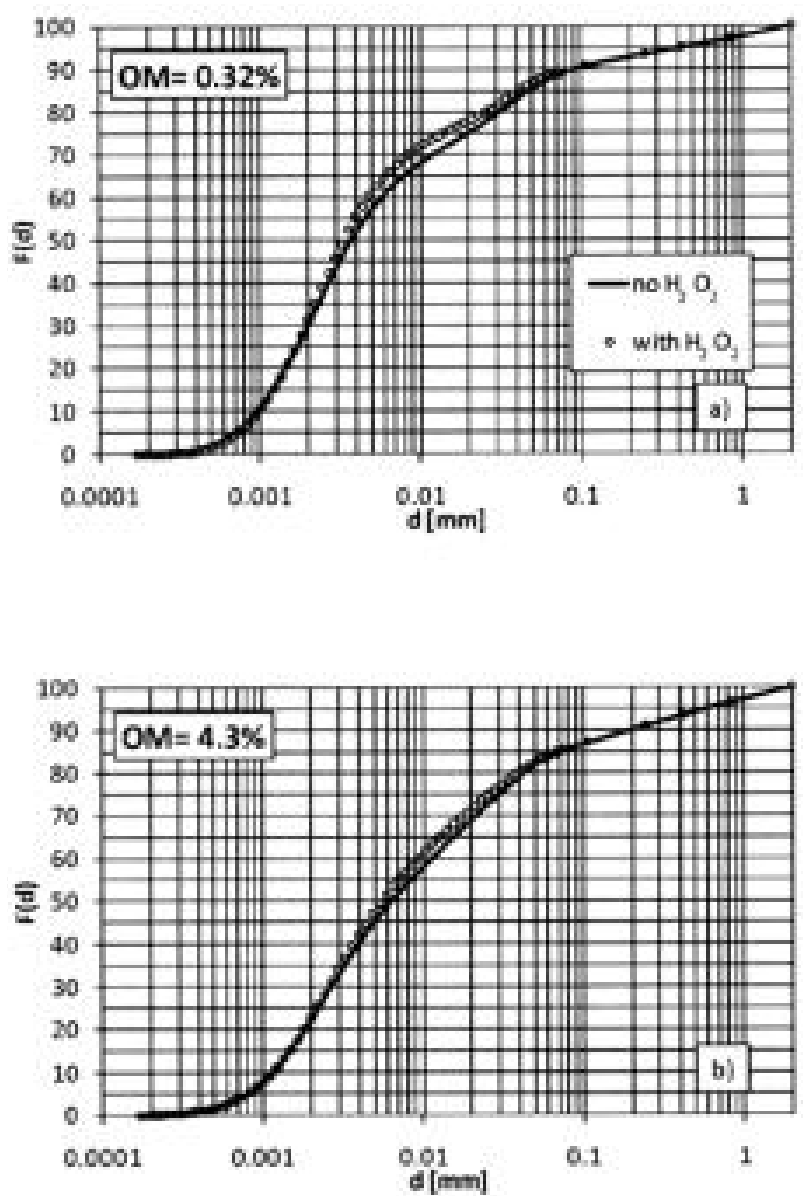

Fig. 4 - Particle size distributions corresponding to different ultrasonic durations.
According to these results, the grain-size distributions of the investigated samples were determined using the Fraunhofer diffraction model.

Figure 8 shows the comparison, for eight soil samples having a different USDA texture classification, between the PSD determined by SHM and LDM. This figure shows that for each sample appreciable difference can be detected between the two methods used to determine the particle size distribution. In particular, for all samples, the Sieve-Hydrometer methods determines a light overestimation of the sand content and an appreciable overestimation of the clay percentage.

Figure 9, which compares the sand content determined with SHM, named $S A_{S H M}$, with the Laser Dif-
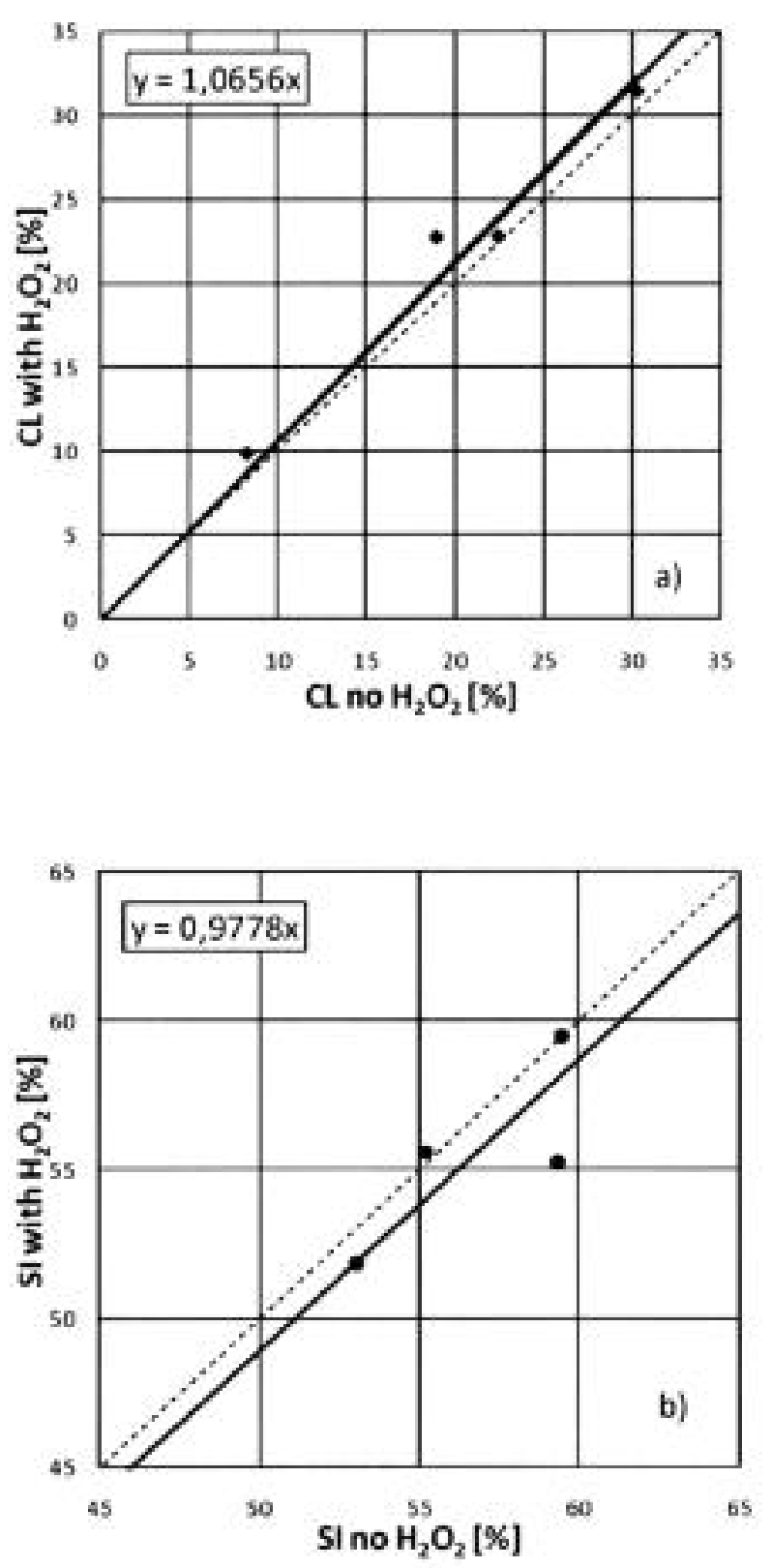

Fig. 5 - Comparison between clay (a) and silt (b) fractions with or without $\mathrm{H}_{2} \mathrm{O}_{2}$ pretreatment. 

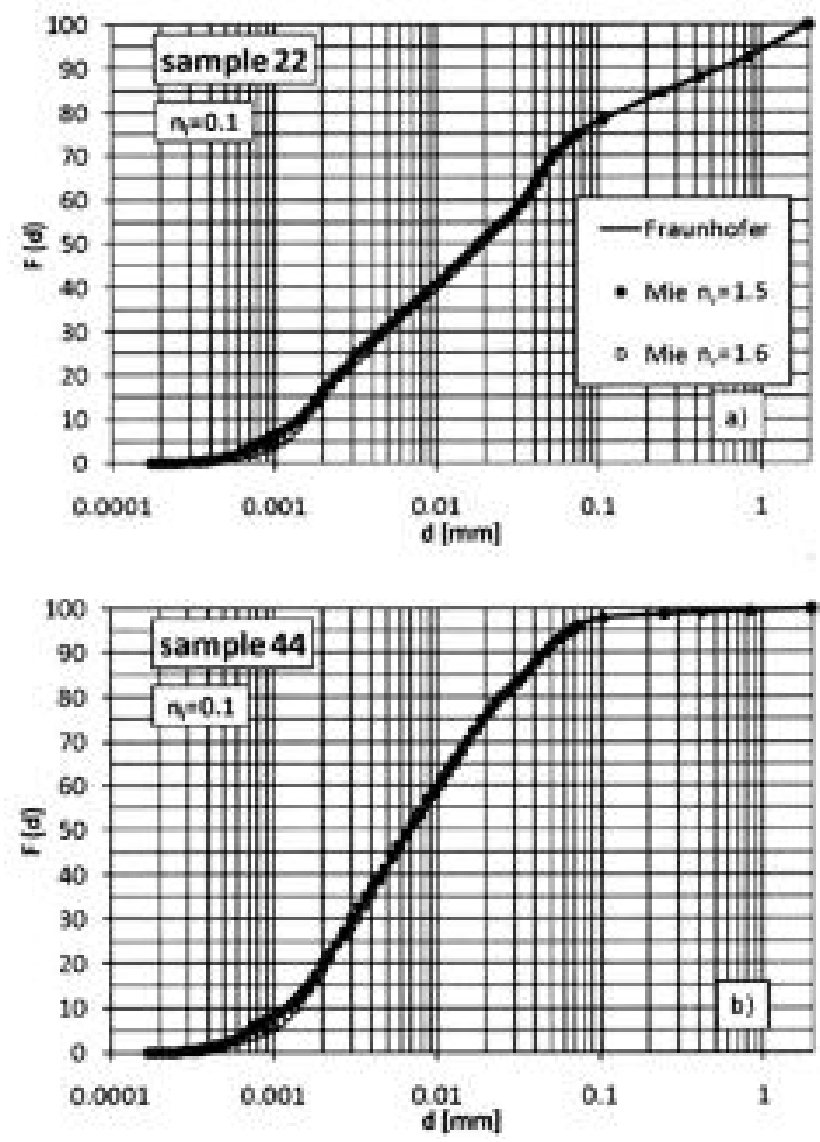

Fig. 6 - Comparison between particle size distributions obtained by Fraunhofer and Mie theory.

fraction measured sand content, $S A_{L D M}$, shows that the two percentages can be assumed equal:

$$
S A_{S H M} \cong S A_{L D M}
$$

while for the clay fraction the following equation can be established:

$$
C L_{S H M}=2.34 C L_{L D M}
$$

in which $C L_{S H M}$ and $C L_{L D M}$ are, respectively, the clay percentage determined by Sieve Hydrometer and Laser Diffraction Methods (Figure 10).

Using of eqs. (1) and (2) allows to obtain the following estimate, $S I_{E}$, of silt percentage:

$$
S I_{E}=100-\left(2.34 C L_{L D M}+S A_{L D M}\right)
$$

Figure 11 shows that a good agreement exists between the silt content $S I_{E}$ estimated by eq. (3) and the percentage $S I_{S H M}$ measured by sieve-hydrometer method.Taking into account that SHM has been adopted as an international standard to determine quantitatively the PSD of soils [Cooper 1994], eqs. (1), (2) and (3) allow to refer the Laser Diffraction measurements to this standard.
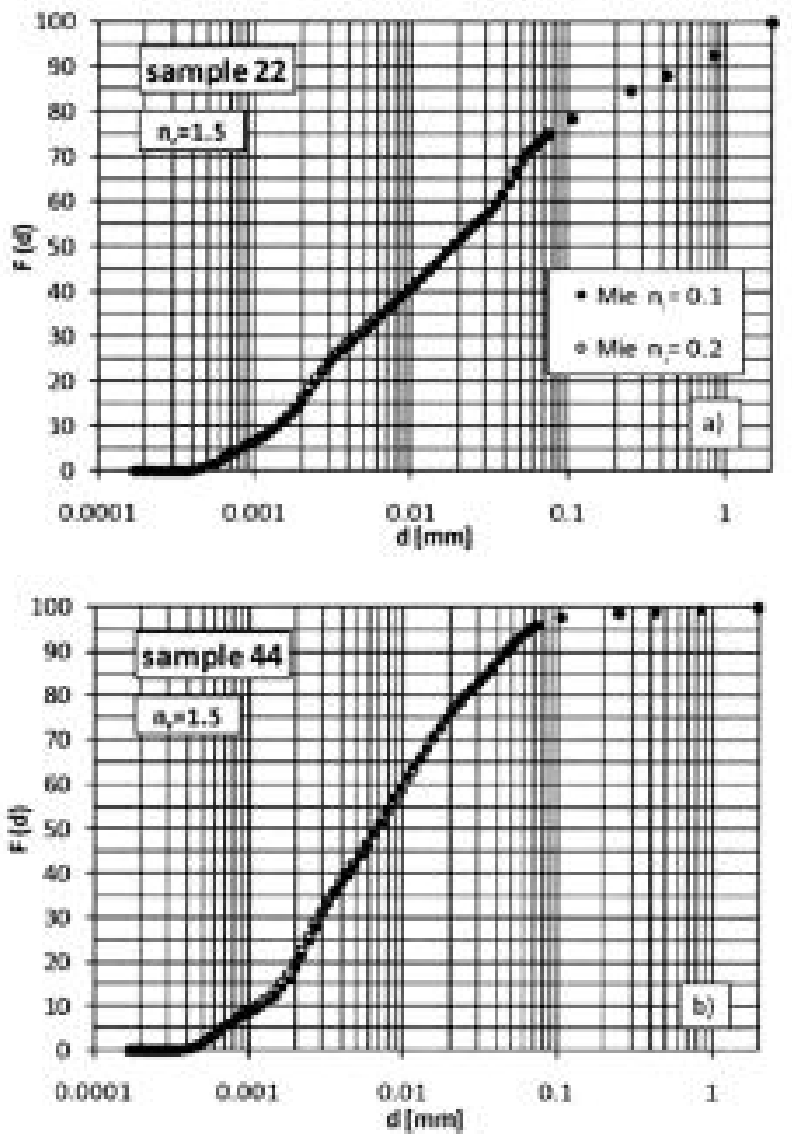

Fig. 7 - Comparison between PSD obtained by Mie theory with two different rifraction index values.

\section{Conclusion}

This paper try to solve the question of how similar the laser grain-size measurements are to those obtained by a classic technique such as Sieve-Hydrometer method. The analysis, developed using 30 soil samples having a different texture classification and sampled in Sicily, allowed to establish:

(a) no reliable differences are determined into the particle size distribution using different ultrasonic duration values;

(b) the effect of the $\mathrm{H}_{2} \mathrm{O}_{2}$ pretreatment is not negligible;

(c) no appreciable differences can be detected for the investigated soils using Fraunhofer and Mie diffraction models;

(d) the sand content measured by Sieve-Hydrometer method can be assumed equal to the one determined by Laser Diffraction technique;

(e) the Sieve-Hydrometer method systematically overestimated the clay fraction respect to the Laser Diffraction method.

Finally a set of equations useful to refer the Laser Diffraction measurements to the Sieve-Hydrometer method, which is used as an international standard, is also proposed.

Further measurements contemporaneously carried out by Laser Diffraction and Sieve-Hydrometer meth- 

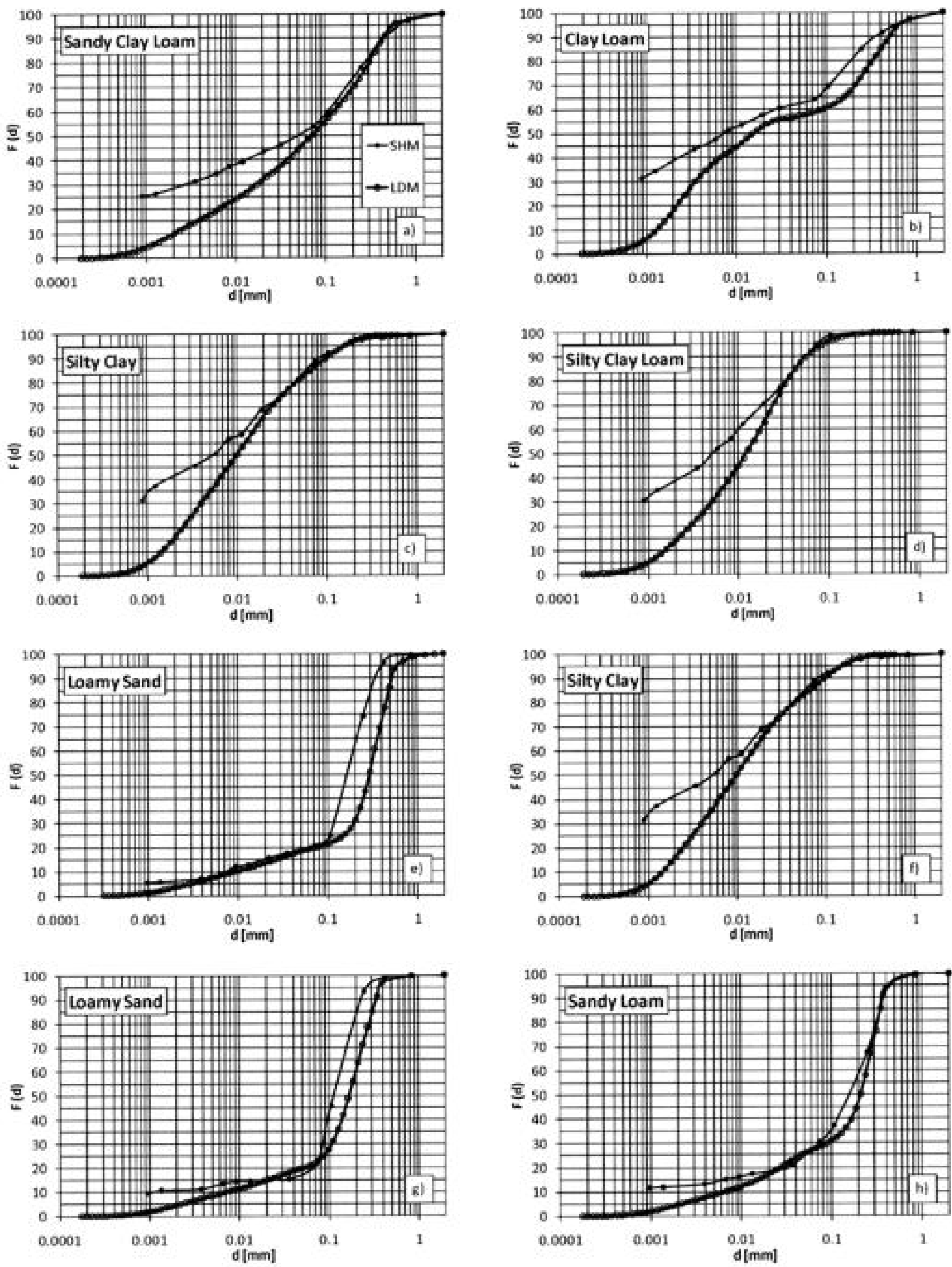

Fig. 8 - Comparison between particle size distributions obtained by Sieve-Hydrometer and Laser diffraction Method. 


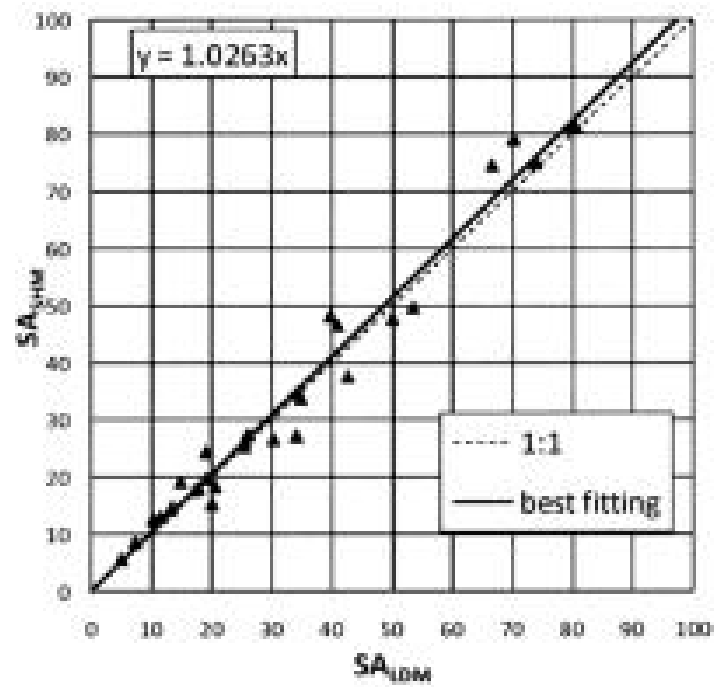

Fig. 9 - Relationship between sand fraction obtained by LDM and the one measured by SHM.

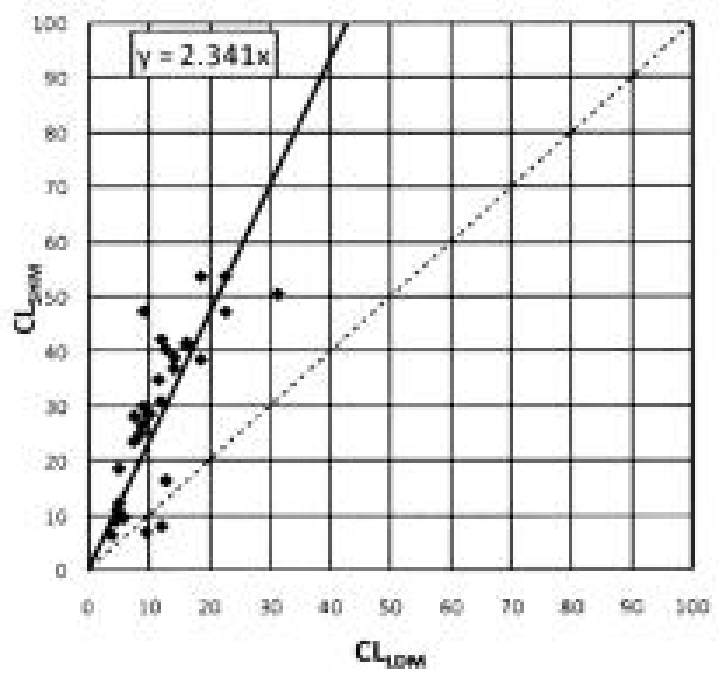

Fig. 10- Relationship between clay fraction obtained by LDM and the one measured by SHM.

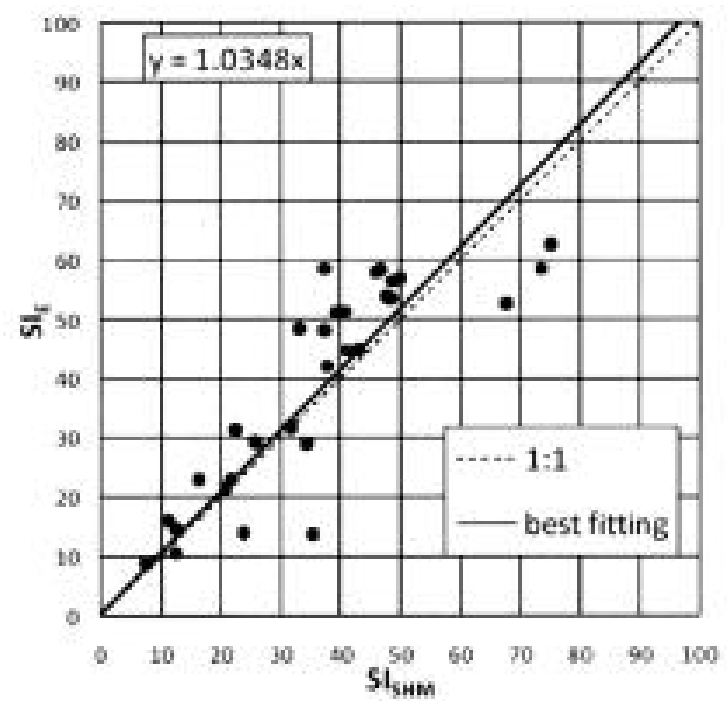

Fig. 11 - Comparison between silt fraction estimated by eq.(3) and the one measured by SHM. ods will allow to confirm the results obtained in this investigation and to test the proposed scale equations.

\section{Acknowledgements}

The research was set up by Prof. Ferro and the measurements were carried out by Dr. Mirabile.

Both Authors analyzed the results and contribute to write the paper.

The research was supported by a grant of Agenzia Regionale per la Protezione Ambientale (ARPA-Sicilia) and FEROS Project.

\section{References}

Allen T.A., Particle Size Measurement. 4th ed., Chapman and Hall, 1990, London, UK.

Bernhardt C., Particle Size Analysis: Classification and Sedimentation Methods. Chapman and Hall, 1994, London, UK.

Beuselinck L., Govers G., Poesen J., Degraer G., Froyen L., 1998. Grain-size analysis laser diffractometry: Comparison with the sieve-pipette method. Catena, 1998, 32, 193-208.

Buurman P., Pape Th., Muggler C.C., Laser grain-size determination in soil genetic studies. 1. Practical problems. Soil Sci., 1997, 162, 211-218.

Chappel A., Dispersing sandy soil for the measurement of particle size distributions using optical laser diffraction. Catena, 1998, 31, 271-218.

Clifton J., Mcdonald P., Plater A., Oldfield F., An investigation into the efficiency of particle size separation using Stokes' Law. Earth Surface Processes and Landforms, 1999, 24, 8, 725-730.

Cooper L.R., Haverland R.L., Vendricks D.M., Knisel W.G., Microtac particle-size analyzer: An alternative particle-size determination method for sediment and soils. Soil Sci., 1984, 138, 138-146.

de Boer G.B., de Weerd C., Thoenes D., Goossens H.W., Laser diffraction spectrometry: Fraunhofer versus Mie scattering. Particle Charac., 1987, 4, 14-19.

Di stefano C., Ferro V., Linking clay enrichment and sediment delivery processes. Biosystems Engineering, 2002, 81, (4), 465-477.

Eshel G., Levy G.J., Mingelgrin U., Singer M.J., Critical evaluation of the use of laser diffraction for particle-size distribution analysis. Soil Sci. Soc. Am. J., 2004, 68, 736-743.

Foster G.R., Young R.A., Neibling W.H., Sediment composition for nonpoint source pollution analyses. Transactions of the ASAE, 1985, 28, 133-146.

Gee G.W., Bauder J.W., Particle-size analysis. p. 383-411. In A. Klute (ed.) Methods of soil analysis. Part 1. 2nd ed. Agron. Monogr. 9. ASA and SSSA, 1986, Madison, WI.

Konert M., Vandenberghe J., Comparison of Laser Grain Size Analysis with Pipette and Sieve Analysis: A Solution for the Underestimation of the Clay Fraction. Sedimentology, 1997, 44, 523-525. 
Liu T.K., Odell R.T., Etter W.C., Thornburn T.H., Comparison of clay contents determined by hydrometer and pipette methods using reduced major axis analysis. Soil Sci. Soc. Am. Proc., 1966, 30, 665-669.

Loizeau J.L., Arbouille D., Santiago S., Vernet J.P., Evaluation of a wide range laser diffraction grain size analyzer for use with sediments. Sedimentology, 1994, 41, 353361.

Lu. N., Ristow G.H., Likos W.I., The Accuracy of Hydrometer Analysis for Fine-Grained Clay Particles. Geotechnical Testing Journal, 2000, 23, 4, 487-495.

McCave I.N., Bryant R.J., Cool H.F., Coughanowr C.A., Evaluation of a laser-diffraction-size analyser for use with natural sediments. J. Sedimentol. Petrol., 1986, 56, 561-564.

McCave I.E., Syvitski J.M.P., Principles and Methods of Geological Particle Size Analysis. In: Principles, Methods and Application of Particle Size Analysis, J. M. P. Syvitski, 1991, Ed., Cambridge University Press, Cambridge, UK, 3-21.

Nettleship I., Cisko L., Vallejo L.B., Aggregation of Clay in the Hydrometer Test. Canadian Geotechnical Journal, 1997, 34, 621-626.

Pieri L., Bittelli M., Pisa P.R., Laser diffraction, transmission electron microscopy and image analysis to evaluate a bimodal Gaussian model for particle size distribution in soils. Geoderma, 2006, 135, 118-132.

Vitton S.J., Sadler L.Y., Particle-Size Analysis of Soils Using Laser Light Scattering and X-Ray Absorbition Technology. ASTM: Geotechnical Testing Journal, 1997, 20, 63-73.
Walter N.F., Hallberg G.R., Fenton T.S., Particle size analysis by the Iowa State Univ. Soil Survey Lab. p. 6174. In G.R. Hallberg (Ed.) Standard procedures for evaluation of quaternary materials in Iowa, 1978, Iowa Geological Survey, Iowa City.

Wen B., Aydin A., Duzgoren-Aydin N.S., A comparative study of particle size analyses by sieve-hydrometer and laser diffraction methods. Geotechnical Testing Journal, 2002, 25, (4), 434-442.

\section{SUMMARY}

In this paper a brief review of the laser diffraction method is firstly carried out. Then, for 30 soil samples having a different texture classification sampled in $\mathrm{Si}$ cilian basin, a comparison between the two techniques is developed.

The analysis demonstrated that the sand content measured by Sieve-Hydrometer method can be assumed equal to the one determinated by laser diffraction technique while an overestimation of the clay fraction measured by Sieve-Hydrometer method respect to laser diffraction technique was obtained.

Finally a set of equations useful to refer LD measurements to $\mathrm{SH}$ method was proposed.

Keywords: Particle-size distribution, Sieve-Hydrometer method, Laser Diffraction method. 
005_Ferro(536)_35 3-09-2009 14:39 Pagina 44

$\phi$ 